\title{
Obituary
}

\section{Obituary for Prof. Dr. Gottfried Heinisch}

\author{
Helmut Viernstein, on behalf of the Austrian Pharmaceutical Society
}

Department of Pharmaceutical Technology and Biopharmaceutics, Faculty of Life Sciences, University of Vienna, Althanstrasse 14, A-1090 Vienna, Austria; helmut.viernstein@univie.ac.at

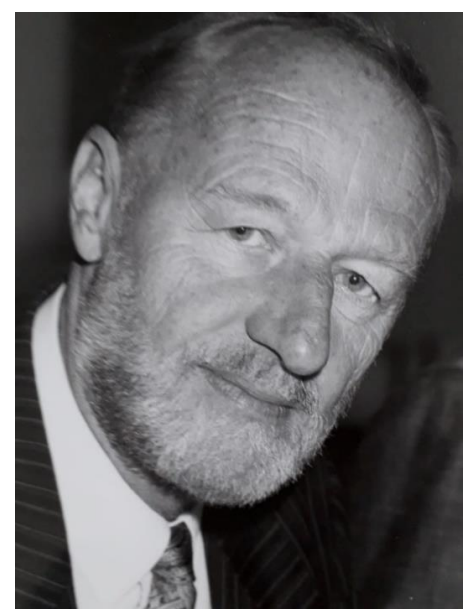

Prof. Dr. Gottfried Heinisch

On 19 September 2019, the Pharmaceutical Science community in Austria lost a distinguished luminary, O. Univ.-Prof.i.R. Dr. Dr.h.c. Mag. pharm. Gottfried Heinisch, at the age of eighty after a long, severe illness.

Born in 1938 to a Lower-Austrian Pharmacist's family, Gottfried Heinisch studied pharmaceutical sciences at the University of Vienna, initially with the perspective of becoming a Pharmacist himself. However, he soon became fascinated by the world of academic research and teaching, and without any hesitation accepted an offer to begin a $\mathrm{PhD}$ dissertation on a topic related to morphine chemistry under the supervision of Prof. Dr. F. Vieböck and successfully obtained his "Dr. phil." in 1968, whereupon he commenced a highly successful academic career. In 1975, he attained his habilitation ("venia docendi") for the discipline of Pharmaceutical Chemistry at the University of Vienna with ground-breaking research in the field of pyridazine chemistry that remained the focus of his research activities throughout his academic life where he achieved international recognition as one of the leading experts in the field, though several other areas of pharmaceutical relevance (including topics in Pharmaceutical Analysis) broadened the spectrum of his research. Following his appointment as "Professor Extraordinarius" (Assoc. Prof.) in 1978 at the Institute of Pharmaceutical Chemistry, University of Vienna he spent many successful years there (the Alma Mater Rudolphina) before accepting a call as full professor ("Professor Ordinarius") at the University of Innsbruck in 1991, where he became the Chair of Pharmaceutical Chemistry. After resolving various administrative and subsidiary issues, he succeeded in establishing an independent Institute of Pharmaceutical Chemistry at the University of Innsbruck in 1993, thus achieving full emancipation from the Organic Chemistry unit. As in his Vienna years, Gottfried Heinisch assembled a group of highly motivated colleagues who contributed to his internationally recognized scientific oeuvre. Following retirement in 1998, Gottfried Heinisch enjoyed some years in good health, which lamentably changed too early. 
What remains wholly unarticulated in the above chronology of his academic career is the fascinating personality of Gottfried Heinisch that manifested itself in multiple ways.

He was a passionate, highly motivated, and galvanizing professor. Those attending his lectures and presentations experienced fireworks of enthusiasm for science, research, and academic mentoring. His spirit was highly infective and undeniably prompted many of his coworkers to set their own first steps into the same direction. Countless Austrian pharmacists still remember his brilliant lessons and presentations. Furthermore he ceaselessly had an open ear and open mind for the wishes and suggestions of his students who adored his style.

He was an amazingly gifted author and presenter. Hardly anybody could write publications in such a manner as he did, continually trying to present a "good story" that was a real pleasure to read. Only on rare occasions did his more than one hundred manuscripts need revisions before they were accepted for publication. Not only his writing style, but also (and maybe even more so) his scientific talks fascinated audiences with legendary enthusiasm and overwhelming engagement. His reputation as a brilliant presenter had its roots in more than 160 invited lectures and oral conference presentations around the globe.

His scientific work, academic mentoring, publications, and presentations all fell on fertile ground. More than 120 supervised master theses, more than 30 supervised $\mathrm{PhD}$ dissertations, and four former coworkers achieved habilitation for Pharmaceutical Chemistry-this speaks for itself. In recognition of his achievements, he was awarded the "doctor honoris causa" degree of the Semmelweis University of Budapest in 2001.

Gottfried Heinisch was a paramount visionary; some of his (initially perhaps utopian) didactic concepts have become reality nowadays, implemented mostly by later generations of Professors. By way of example he innovated, the "vertical" organization of lecture clusters in which a given topic is covered by a group of experts from different pharmaceutical disciplines, thus explaining all relevant aspects in a collaborative manner. It was precisely this interdisciplinary approach that he persistently had on his mind.

In his constant engagement for an up-to-date and practice-oriented academic training, he was convinced that a profound scientific education was absolutely essential for any kind of pharmaceutical professional activity. This was one motivation to initiate, together with Prof. Dr. Wolfgang Kubelka, the foundation of the Austrian Pharmaceutical Society in 1979 and serve as the society's president for several years.

He was a mentor in the best of senses; forever demanding and strict, though always just and admirably attempted to create "win-win" situations with new opportunities for personal development for the people around him. He never obstructed anybody else's ambitions for selfish motives, yet he never remained silent when it was necessary to criticize various shortcomings in commonplace academic life or erroneous developments within the university. He credibly attempted to avoid making such mistakes himself. Over the years he witnessed many of his closest coworkers successfully commencing and continuing their own careers in academia, industry, or elsewhere, and was proud of them.

Among multiple interests, his passion for travelling and exploration of remote geographical areas combined with a remarkable talent for photography, was well-known. As a result, his creative slideshows of travel experiences and adventures were popular among different audiences, including many Austrian Pharmacists at their regular meetings for vocational training.

The energy to give as much as possible in his role as a scientist, a researcher, mentor, and the power to inspire and motivate people had a major source that was his love of family and the love his family gave to him. With his passing, a painful gap will remain in every respect. What will endure is our cherished memory of Gottfried Heinisch that is filled with deep gratitude. 